\title{
Thermoelectricity - A Promising Complementarity with Efficient Stoves in Off-grid-areas
}

\author{
Camille Favarel', Daniel Champier ${ }^{* 2}$, Jean-Francois Rozis ${ }^{3}$, Tarik Kousksou ${ }^{4}$, Jean \\ Pierre Bédécarrats ${ }^{5}$ \\ ${ }^{1}$ Laboratoire de Thermique, Energétique et Procédés (LaTEP), Univ Pau \& Pays Adour, Avenue de \\ l'Université BP 576, Pau, France \\ e-mail: Camille.favarel@univ-pau.fr \\ ${ }^{2}$ Lab. des Sciences de l'Ingénieur Appliquées à la Mécanique et au Génie Electrique (SIAME), Univ Pau \& \\ Pays Adour, Avenue de l'Université BP 576, Pau, France \\ e-mail: daniel.champier@univ-pau.fr \\ ${ }^{3}$ Planète Bois, 17 bis route de Toulouse 65690 Barbazan Debat, Tarbes, France \\ e-mail: rozisjf@planetebois.org \\ ${ }^{4}$ Lab. des Sciences de l'Ingénieur Appliquées à la Mécanique et au Génie Electrique (SIAME), Univ Pau \& \\ Pays Adour, Avenue de l'Université BP 576, Pau, France \\ e-mail: Tarik.kousksou@univ-pau.fr \\ ${ }^{5}$ Laboratoire de Thermique, Energétique et Procédés (LaTEP), Univ Pau \& Pays Adour, Avenue de \\ l'Université BP 576, Pau, France \\ e-mail: jean-pierre.bedecarrats@univ-pau.fr
}

Cite as: Favarel, C., Champier, D., Rozis, J-F., Kousksou, T., Bédécarrats, J. P., Thermoelectricity - A Promising Complementarity with Efficient Stoves in Off-grid-areas, J. sustain. dev. energy water environ. syst., 3(3), pp 256-268, 2015, DOI: http://dx.doi.org/10.13044/j.sdewes.2015.03.0020

\begin{abstract}
Thermoelectric modules produce electricity from heat flow. In areas without electricity, biomass is generally burnt in open fires or rudimentary stoves in order to generate heat, to cook and to produce domestic hot water. Combustion quality in these devices is very low and needs a large amount of wood extracted from surrounding forests. "Planète Bois" develops highly efficient clean multifunction stoves based on double chamber combustion. As an exhaust fan is necessary to adjust the primary and secondary air flows for optimal combustion, these stoves cannot currently be used without electricity. Thermoelectric modules incorporated in a heat exchanger between the flue and the hot water tank can supply the exhaust fan and also produce some electricity for other basic purposes. Our paper presents tests that were done on one of these stoves to size the thermoelectric generator and thus the produced electricity. These preliminary tests are used to identify an outlook for the successful implementation of these stoves.
\end{abstract}

\section{KEYWORDS}

Thermoelectric generator, Thermoelectric module, Efficient stove, Multifunction stove, Combustion, Off-grid system.

\section{INTRODUCTION}

The Thermoelectric (TE) effect allows us to produce electricity from heat flow. This is achieved by using thermoelectric modules, often called Seebeck modules. Current modules, made of Bismuth telluride, with an area of about a few tens of square centimeters, can produce a few watts with a relatively low efficiency of the order of a few percent. Because of their low efficiency, the TE modules are performing generators only

\footnotetext{
* Corresponding author
} 
in the following cases: use of a free source of energy like the sun, wasted heat recovery or use of a combined heat and power system.

In areas without electricity, biomass is generally burnt in open fires or rudimentary stoves in order to generate heat, to cook and to produce domestic hot water. Combustion quality is generally very low and needs a large amount of wood extracted from surrounding forests.

The non-profit technology development platform "Planète Bois" develops highly efficient stoves based on double-chamber combustion design for burning non-processed fuelwood. These stoves are multifunctional (heating, cooking and hot water). For these efficient stoves, an exhaust fan is necessary to adjust the primary and secondary air flows for optimal combustion conditions at nominal defined power. Hot water storage, ergonomics and clean cooking conditions make this equipment very attractive and convenient for rural women. However, this type of stove cannot currently be used in areas without electricity. Using a Thermoelectric Generator (TEG), enough electric power would be generated in order to supply the exhaust fan and also to produce some electricity for other basic purposes. Due to the specific geometry of "Planète Bois" stoves, it is possible to use a heat exchanger incorporating TE modules between the flue and the hot water tank. Cogeneration is therefore achieved and the conversion efficiency is no more a barrier, the question is only to get enough electrical power.

In order to increase the electrical power generated, the heat flow through the heat exchanger has to be increased and as a consequence the temperature on the hot side of the TE module increases too. A major difficulty for the use of TEGs is the trade-off between the heat flow through the modules and the acceptable temperature range for the current thermoelectric materials.

In this introduction, at first the properties of the TEGs are presented. In a second part the specifications of the "Planète Bois" stove [1] are developed. The coupling between the TEG and the stove is presented.

The following section describes the experimental assembly in order to characterize the performance of heat exchangers. The last section presents the first results of the measurement as well as an estimate of the electrical energy which can be produced by the stove.

\section{Thermoelectric generators}

TEGs directly convert into electricity a part of the heat energy which flows through them. The main component of these devices is the TE module or Seebeck module (Figure 1), which usually contains some tens to hundreds of TE couples connected electrically in series and thermally in parallel. Other elements which surround this module, are however essential for an industrial use of the module: the heat exchangers which amplify the heat transfer through the modules and the electronic DC/DC convertors which regulate the output voltage.

A TEG is a sort of heat engine that works by transferring energy from a hot source to a cold sink and converts part of this heat into electricity.

The efficiency $\eta_{\mathrm{TE}}$ of a TE module, which is the ratio of the electrical energy produced $\left(W_{\text {elec }}\right)$ to the heat $\left(Q_{\mathrm{H}}\right)$ reaching the hot side of the module, is given by the following formula [2]. This formula is obtained under the assumption that the TE material properties are constant:

$$
\eta_{\mathrm{TE}}=\frac{W_{\text {elec }}}{Q_{\mathrm{H}}}=\frac{\Delta T}{T_{\mathrm{h}}} \times \frac{\frac{m}{m+1}}{1+\frac{(m+1)}{z T_{\mathrm{hh}}}-\frac{\Delta T}{2 T_{\mathrm{h}} \times(m+1)}}
$$


With $T_{\mathrm{h}}$ the temperature of the hot side of the TE module, $T_{\mathrm{c}}$ the temperature of the cold side of the module, $\Delta T=T_{\mathrm{h}}-T_{\mathrm{c}}$ the temperature difference, $z$ is the factor of merit of the TE material and $m$ is the ratio of the electrical load resistance to the internal resistance of the TE module.

The maximal efficiency is obtained for an optimal ratio $m_{\mathrm{opt}}$ and yields:

$$
\eta_{\mathrm{TE}_{\max }}=\frac{W_{\text {elec }}}{Q_{\mathrm{H}}}=\frac{\Delta T}{T_{\mathrm{h}}} \times \frac{\sqrt{1+z T-1}}{\sqrt{1+z T}+\frac{T_{\mathrm{c}}}{T_{\mathrm{h}}}} \quad m_{\mathrm{opt}}=\sqrt{1+z T}
$$

where $T$ is the average temperature in $\mathrm{K}$.

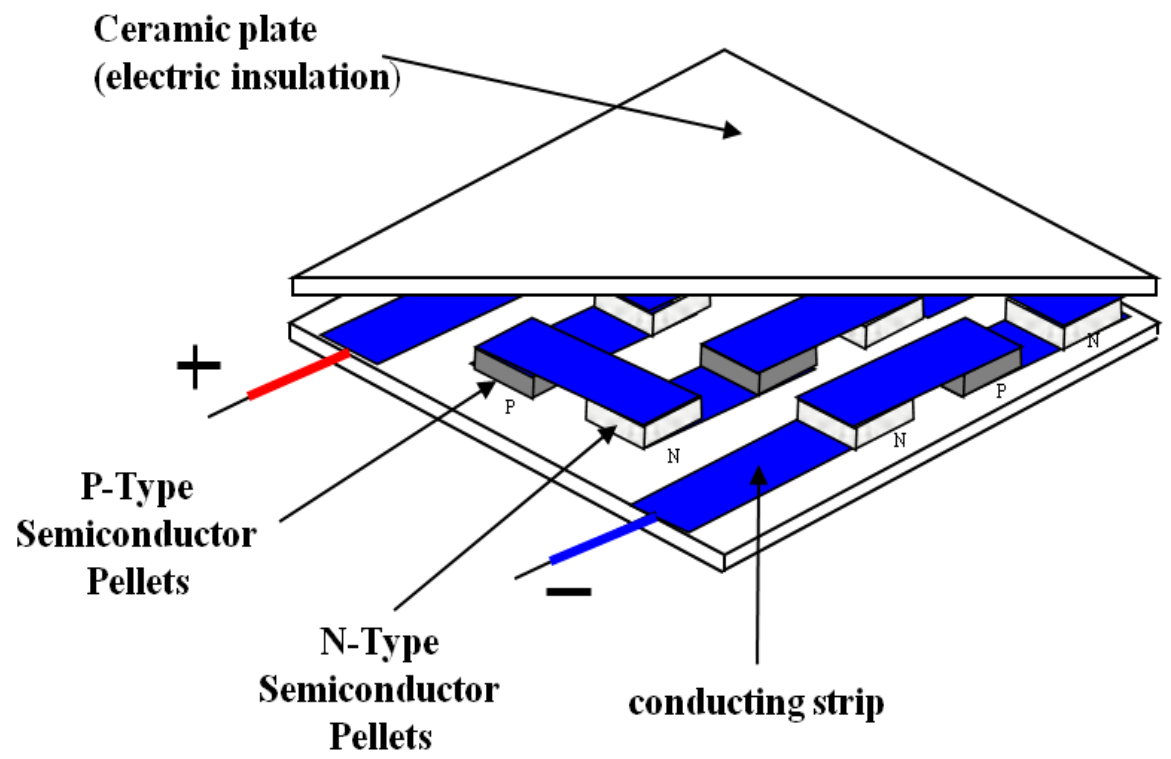

Figure 1. Schematic of a TE module

Figure 2 shows the expected efficiency for different values of the figure of merit $z T$. Commercially available $\mathrm{Bi}_{2} \mathrm{TE}_{3}$ module has a maximum figure of merit around 1 . In the laboratory a figure of merit higher than 2 has been reported [3] but it will be a long time before it is commercially available. Due to the fact that the figure of merit is not constant but is a function of the temperature, it is more correct to take into account an average figure of merit. This average figure of merit is reasonably between 0.5 and 0.8 for commercially available modules. The modules that we use from Thermonamic have an efficiency of about $5 \%$ for a difference of temperature of $270 \mathrm{~K}$ which corresponds to an average $z T$ of 0.5 .

Figure 2 clearly shows the low efficiency of the TE modules. However TE modules present other advantages which compensate extensively for their low efficiency. TE modules have no moving parts, no working fluids, they are noiseless and they need no maintenance. For example, they have been used in space for many years [4-6].

TE modules become very interesting generators in the following cases: use of a free source of energy like the sun, wasted heat recovery or use of a combined heat and power system, low level of electrical power production $(<100 \mathrm{~W})$ where other thermodynamic engines are deficient. Research is particularly active in the automotive field where TE modules are one of the possible solutions to get back the waste heat from exhaust gases [7-10]. 


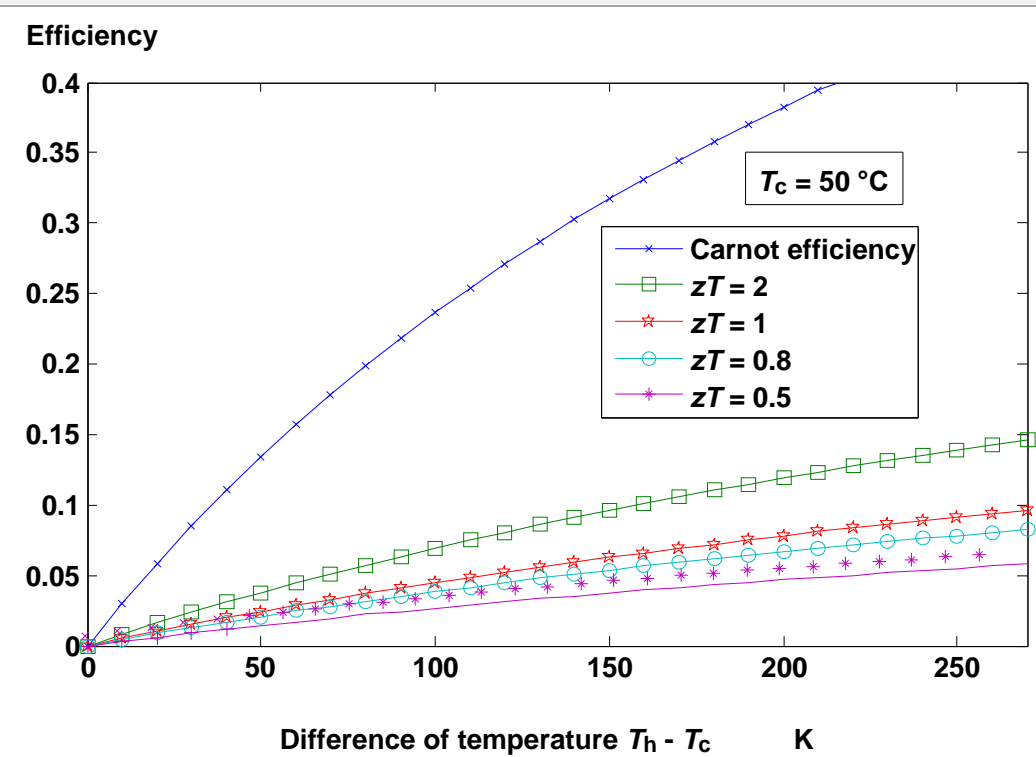

Figure 2. Efficiency versus difference of temperature

\section{"Planète Bois" multifunction clean stove}

In areas without electricity, biomass is generally burnt in open fires or rudimentary stoves in order to generate heat, to cook and to produce sanitary hot water. Wood is used in $90 \%$ of rural households for their daily activities: baking bread, cooking, water heating and room heating in winter. Combustion quality is generally very low and needs a large amount of wood extracted from surrounding forests. Very widespread, traditional equipment (bread oven in Roman type, fireplace with "three cooking stones" and brazier) are characterized by a very low efficiency (5-10\%) and the emission of black fumes harmful to users and to the environment.

Collecting firewood usually contributes to increased pressure on natural forests. Although this activity is very expensive in manpower, it continues to be practiced by low income families because the firewood is free.

"Planète Bois" develops low cost, long lasting and highly efficient clean stoves based on a double chamber combustion design (900-1000 ${ }^{\circ} \mathrm{C}$ flame temperature, maximum CO level of $200 \mathrm{~g} / \mathrm{GJ}, 85 \%$ global efficiency). These stoves are multifunctional (heating, cooking and hot water) and made with locally available building materials.

Figure 3 shows the different parts of the stove:

- The pyrolysis chamber where the wood is gasified. The quantity of oxygen, coming from the primary air inlet tubes, going into this chamber is just small enough to maintain the heat generated by the embers to continue the gasification;

- The mixing zone where wood gas is mixed with oxygen. The particular geometry of this zone increases the speed of the gas flow and improves its mixing with oxygen. The secondary air is pre-heated by the metal tubes going along the combustion chamber;

- The combustion chamber is the place of flame development. Due to turbulent air/gas mixing, the high temperature and the appropriate reaction time, most of the volatile matter is combusted in this additional combustion chamber;

- The first heat exchanger with the cooking pan and pot;

- The second heat exchanger between the hot gas and the water tank. This exchanger includes the TEG;

- The electro-mechanical extraction which is necessary to extract the smoke at low temperature in the horizontal flue. 
The objective is to reduce the fuelwood consumption by half, that is to go from 14 to $7 \mathrm{~kg}$ of wood per day per household (5 to 6 persons per household) while significantly improving the comfort. The stove uses pruned branches (length $40 \mathrm{~cm}$, diameter between 4 and $8 \mathrm{~cm}$ ).

"Planète bois" has already built these stoves with local masons in Morocco.

The features of the equipment developed in Morocco are:

- Cooking;

- Simultaneous cooking of 2 dishes;

- 2 modes (express or simmering) according to position of the pots.

- Production of domestic hot water;

- Storage in stainless tank allowing hygienic use;

- Important production with multiple uses: showering, cleaning, laundry, dishes. This makes it possible to reduce the use of detergents;

- Effect of energy storage in the water tank: hot water availability between 2 sessions (in particular, hot water availability for morning ablutions).

- Heating;

$\circ$ Low temperature radiant heating (comfort) due to inertia of the stove;

- Design;

- Choice of a mechanical extraction (electric fan) avoiding chimney implementation (less expensive and easier installation - no technical issues).

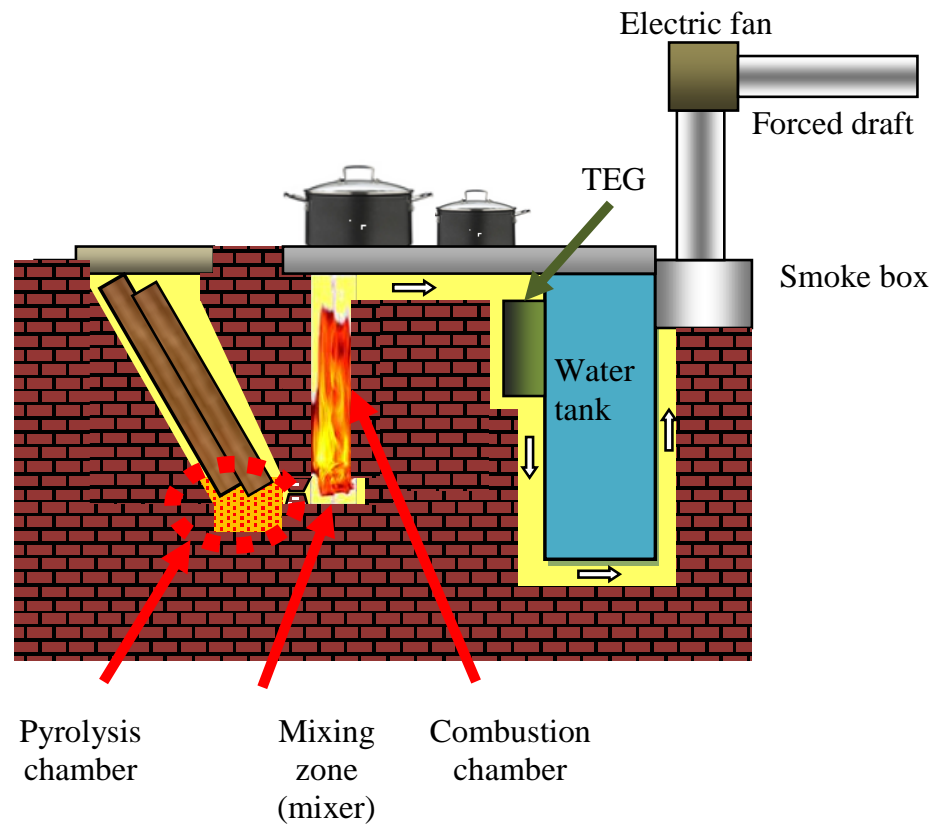

Figure 3. Diagram of the stove

Natural draft cannot be used in such contexts because of:

- The difficulty to realize highly insulated exhaust pipes, the minimal height of $5 \mathrm{~m}$ and the technical complexity of waterproof connections with the roofing;

- A high inlet temperature, around $250{ }^{\circ} \mathrm{C}$, required in the flue-gas stack reduces the global energy performance of the installation;

- The ignition is more difficult due to lack of ventilation when the stove is cold and the transit time to a high performance combustion is longer;

- The cost of installing it is much higher. 
The technical characteristics are presented in Table 1.

Table 1. Stove characteristics

\begin{tabular}{cc}
\hline Power & $6 \mathrm{~kW}$ \\
Domestic hot water production & $30 \mathrm{~L} \mathrm{each} 30 \mathrm{~min}$ \\
Wood consumption & $1.5 \mathrm{~kg}$ per hour \\
Outside dimensions $(1, \mathrm{w}, \mathrm{h})$ & $110 \times 60 \times 85 \mathrm{~cm}$ \\
Life expectancy & 15 years \\
Average efficiency & $80 \%$ \\
\hline
\end{tabular}

For these efficient stoves, the mechanical extraction is done by an electrical exhaust fan. This fan adjusts the primary and secondary air flows for optimal combustion conditions at nominal defined power. In Morocco, further to the program of rural electrification, this stove can be disseminated almost everywhere.

However, this type of stove cannot currently be used in areas without electricity elsewhere in the world. About 1.2 billion people - $20 \%$ of the world's population - are still without access to electricity worldwide, almost all of whom live in developing countries. This includes about 550 million in Africa, and over 400 million in India [11]. The use of a TEG is probably a solution for generating enough electric power in order to supply the fan. It also could produce some electricity for other basic purposes. Due to the specific geometry of "Planète Bois" stoves, it is possible to use a heat exchanger incorporating TE modules between the flue and the domestic hot water tank. Cogeneration is achieved and so the conversion efficiency is no more a barrier, the question is only to get enough electrical power.

\section{TEG and stoves}

A few laboratories have made researches to install some TE modules $\left(\mathrm{Bi}_{2} \mathrm{Te}_{3}\right)$ on cookers or stoves. Masbergen et al. $[12,13]$. studied a TEG using smoke as hot source and the outside air in forced convection as cold source. The electrical power obtained was of the order of $4 \mathrm{~W}$ after the DC/DC controller. Rinalde et al. [14] have studied a TEG using smoke as hot source and a circulation of water as cold sink. The power obtained in laboratory with a module $\mathrm{Bi}_{2} \mathrm{Te}_{3}$ was about $10 \mathrm{~W}$ but the consumption of the pump is not specified and the electronic convertor to store the electricity was not operational. More recently, O'Shaughnessy et al. [15] have developed a prototype electrical generator for portable stoves (chitetezo mbaula stoves) that are widely available across Malawi. The aim was also to reduce the amount of collected fuelwood. The TEG used a heat pipe to collect the heat from the stove and a fan to cool the cold side of the TE module. From laboratory experiments, a maximum TEG power output of $5.9 \mathrm{~W}$ has been obtained. On average, $3 \mathrm{Wh}$ of energy was stored in a battery during a typical $1 \mathrm{~h}$ long burn.

A TEG has been developed in our laboratory to equip stoves $[16,17]$. This TEG designed with one TE module has produced a maximum electrical power of $9.5 \mathrm{~W}$ and because of losses in the electronic DC/DC convertor a maximum power of $7.6 \mathrm{~W}$ was available. An experimental device using a gas heater was setup to replicate the temperatures in the stove. A Maximum Power Point Tracking (MPPT) DC-DC convertor allows us to store the electrical energy either in a $6 \mathrm{~V}$ or in a $12 \mathrm{~V}$ lead acid battery [18]. On average, $18 \mathrm{Wh}$ of energy was stored in the battery during a $2 \mathrm{~h}$ experiment with a TEG which was equipped with 2 TE modules $\left(\mathrm{Bi}_{2} \mathrm{Te}_{3}\right.$ modules from Thermonamic, reference TEP1-12656-0.6). Energy between 35 and 55 Wh could be stored in a battery during a typical day depending on the duration of the two cooking sessions. 
Although this experiment allows us to evaluate the generator's performance, the test conditions do not replicate exactly those that would occur in a wood stove.

\section{Objectives/scope of work}

The objective of the study is to experiment the TEG system into a real biomass stove. The first step is to correctly size the generator in order to produce firstly enough electricity to run the fan and secondly some electricity for evening lighting and phone charging. The important parameter is the output electrical power. The maximum electrical power, using the standard model, is given by [19]:

$$
W_{\max }=F \times n\left(\frac{\alpha^{2}}{2 \rho}\right)\left(\frac{A}{l}\right)\left(T_{\mathrm{h}}-T_{\mathrm{c}}\right)
$$

where $n$ is the number of thermocouples per TE module, $\alpha$ and $\rho$ are the Seebeck coefficient and the electrical resistivity of the thermocouples, $A$ and $l$ their area and their length respectively. $F$ is a fabrication quality factor.

To increase the power, it is necessary to increase the difference of temperature; however $T_{\mathrm{h}}$ is limited by the maximum temperature tolerated by the TE module.

\section{EXPERIMENTAL SETUP}

A wood stove has been built in our laboratory in order to measure the expected power output of TE modules (Figure 4).

The water tank, on which the modules will be put, measures $50 \mathrm{~cm}$ (height) by $25 \mathrm{~cm}$ (width) by $25 \mathrm{~cm}$ (length) and is made of stainless steel.

The generator consists of four sets of two commercially available $\mathrm{Bi}_{2} \mathrm{Te}_{3} \mathrm{TE}$ modules from Thermonamic TEHP1-12656-0.3 placed on the water tank and of four sets of aluminum heat exchangers as described in Figure 4a. The temperature on the hot side of the module can be continuously as high as $330{ }^{\circ} \mathrm{C}$ and intermittently up to $400{ }^{\circ} \mathrm{C}$. The temperature on the cold side of the module must be less than $200^{\circ} \mathrm{C}$ due to the soldering which is different on each side of the module.

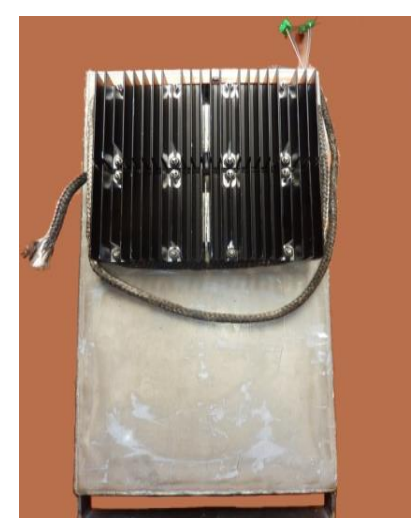

(a)

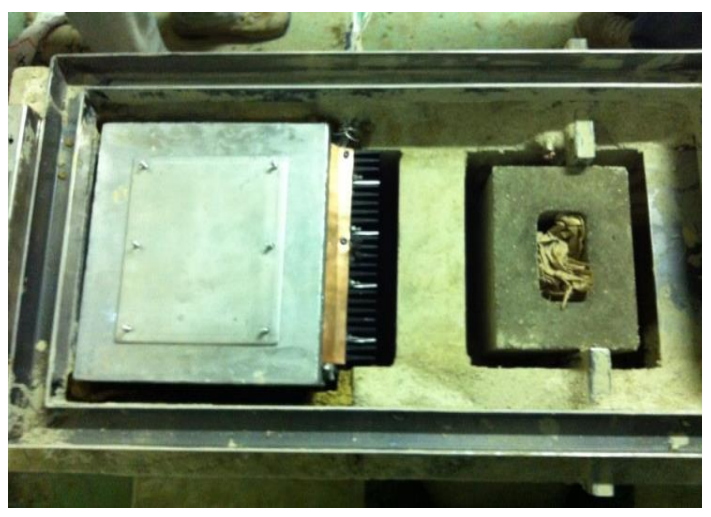

(b)

Figure 4. Water tank with heat exchangers (a); Top view of the tank installed in the stove (b)

The behavior of the stove in different operating conditions should be characterized to determine whether the design of the heat exchanger was correct. Considering the uncertainties on the temperatures and on the flow of smoke, it was necessary to perform a series of tests. To use the TE modules directly was not advisable because of the risks of destruction. An alternative material has been sought. 
The global thermal conductivity $\lambda$ of the module can be calculated from the specification sheet (Table 2):

$$
\lambda=\frac{\Phi \times e}{\left(T_{\mathrm{h}}-T_{\nu}\right) \times I \times W}=2.73 \mathrm{~W} / \mathrm{mK}
$$

and the thermal resistance of the module can also be calculated:

$$
R_{\mathrm{th}}=\frac{\left(T_{\mathrm{h}}-T_{\mathrm{c}}\right)}{\Phi}=0.70 \mathrm{~K} / \mathrm{W}
$$

Table 2. Module specification

\begin{tabular}{ccc}
\hline$T_{\mathrm{h}}$ & Hot side temperature $\left[{ }^{\circ} \mathrm{C}\right]$ & 300 \\
$T_{\mathrm{c}}$ & Cold side temperature $\left[{ }^{\circ} \mathrm{C}\right]$ & 30 \\
$\Phi$ & Heat flow across the module $[\mathrm{W}]$ & 386 \\
$e$ & thickness $[\mathrm{m}]$ & 0.006 \\
$l$ & length $[\mathrm{m}]$ & 0.056 \\
$w$ & width [m] & 0.056 \\
\hline
\end{tabular}

For the test of the stove, the TE modules were replaced by glass ceramic Neoceram $\mathrm{N}-0$. Neoceram $\mathrm{N}-0$ has an average thermal conductivity of $1.82 \mathrm{~W} / \mathrm{mK}$ between $100{ }^{\circ} \mathrm{C}$ and $300{ }^{\circ} \mathrm{C}$. So the thermal resistance of a $0.056 \mathrm{~m} \times 0.056 \mathrm{~m}$ area and $0.004 \mathrm{~m}$ thickness glass plate is also around $0.70 \mathrm{~K} / \mathrm{W}$. The glass ceramic is a cheaper replacement for the TE modules and has been used for the experiment.

Thermocouple temperature sensors are positioned at different locations of the TEG on the hot side of the modules and numbered as described in Figure 5. Two temperature sensors ( $T_{\mathrm{gi1}}$ and $\left.T_{\mathrm{gi} 2}\right)$ are used to measure the temperature of the incoming hot gas on the TEG and one sensor is used for the temperature of the gas at the outlet of the TEG. Finally a temperature sensor is positioned in the tank $\left(T_{\mathrm{w} 2}\right)$, fixed on the wall in order to have an idea of the temperature of wall and of the cold side temperature of the module. For technical reasons, it was not possible to put more sensors in the tank. This sensor was positioned almost in the middle of the TEG.

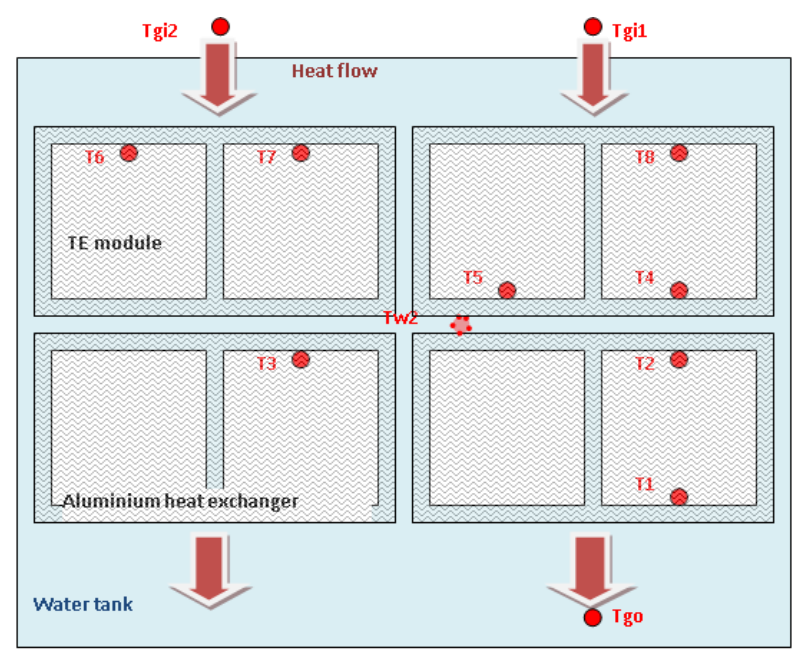

Figure 5. Description of the TEG 
A temperature sensor $\left(T_{\mathrm{fo}}\right)$ is positioned at the top of the flame development chamber and another $\left(T_{\mathrm{so}}\right)$ is positioned in the outlet of the flue of the stove just before the smoke box. These measures are used to verify the proper operation of the stove.

Data acquisition of the temperatures is performed with a standalone data acquisition module AOIP FD5 in which sensor readings are relayed to the computer. The accuracy is the sum of $0.021 \%$ of reading value and $0.7^{\circ} \mathrm{C}$.

\section{RESULTS AND DISCUSSION}

Results for a nominal $2 \mathrm{~h}$ long experiment performed are provided in Figure 6.

As it is biomass combustion, it is unlike the experiments conducted previously [18]. The temperature of gases is very irregular and evolves when some wood is loaded or when the fire is poked. It can be seen that most of the time the temperature at the top of the flaming chamber $\left(T_{\mathrm{fo}}\right)$ is over $800^{\circ} \mathrm{C}$ which is necessary to ensure good combustion. The temperature at the outlet of the stove $\left(T_{\mathrm{so}}\right)$ is around $100-120{ }^{\circ} \mathrm{C}$ which is also characteristic of a very good efficiency. The temperature at the end of the flue (not recorded) was around $60{ }^{\circ} \mathrm{C}$. Almost no heat is released to outside the laboratory. $T_{\text {gi } 1}$ and $T_{\mathrm{go}}$ show the temperature at the inlet and outlet of the exchanger. The difference of temperature of the hot gas along the heat exchanger varies between 200 and $300{ }^{\circ} \mathrm{C}$. Looking at $T_{\mathrm{w} 2}$ is very instructive. During the first period, the temperature increases up to almost $100{ }^{\circ} \mathrm{C}$. At this time, we started to draw some water and to add fresh water, always keeping water in the tank (before the red dotted line). In the last hour of combustion, because of error of manipulation in the draining and the filling of the tank, three peaks of temperature can be observed. This peak occurred when the tank was not completely full so the sensor was no more in the water. The temperature grows up to more than $200{ }^{\circ} \mathrm{C}$ which would have destroyed the TE modules. It clearly shows that it is really important to always keep water over the level of the TEG. This needs to be considered in the future design of the stove.

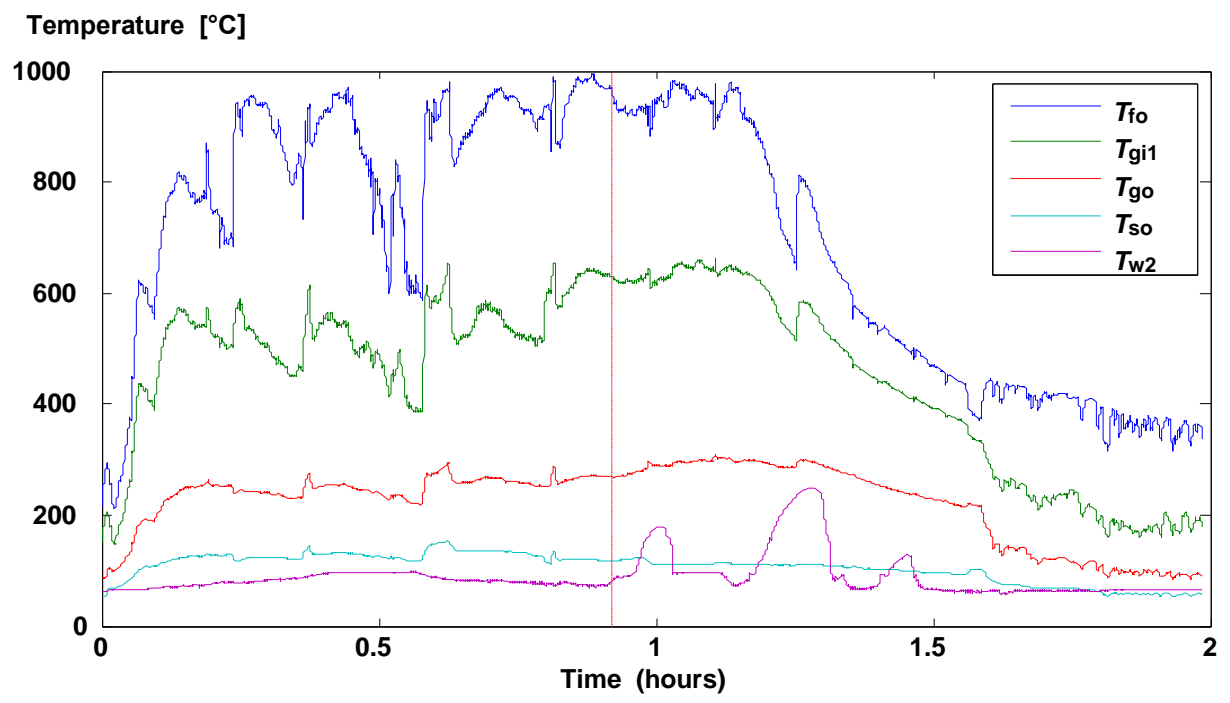

Figure 6. Main temperatures in the stove

Figure 7 details the gas temperatures at the inlet of the heat exchangers and the temperature at the top of each heat exchanger. It may be noted that the temperatures are slightly higher on the left side of the duct. However, this difference is very small and the flow is therefore well distributed on the exchangers. Moreover, the average deviation between the measured temperatures $T_{8}$ and $T_{4}$ and respectively between $T_{2}$ and $T_{1}$ is less 
than $1^{\circ} \mathrm{C}$. This result shows that temperatures will be very uniform on the surface of each TE module.

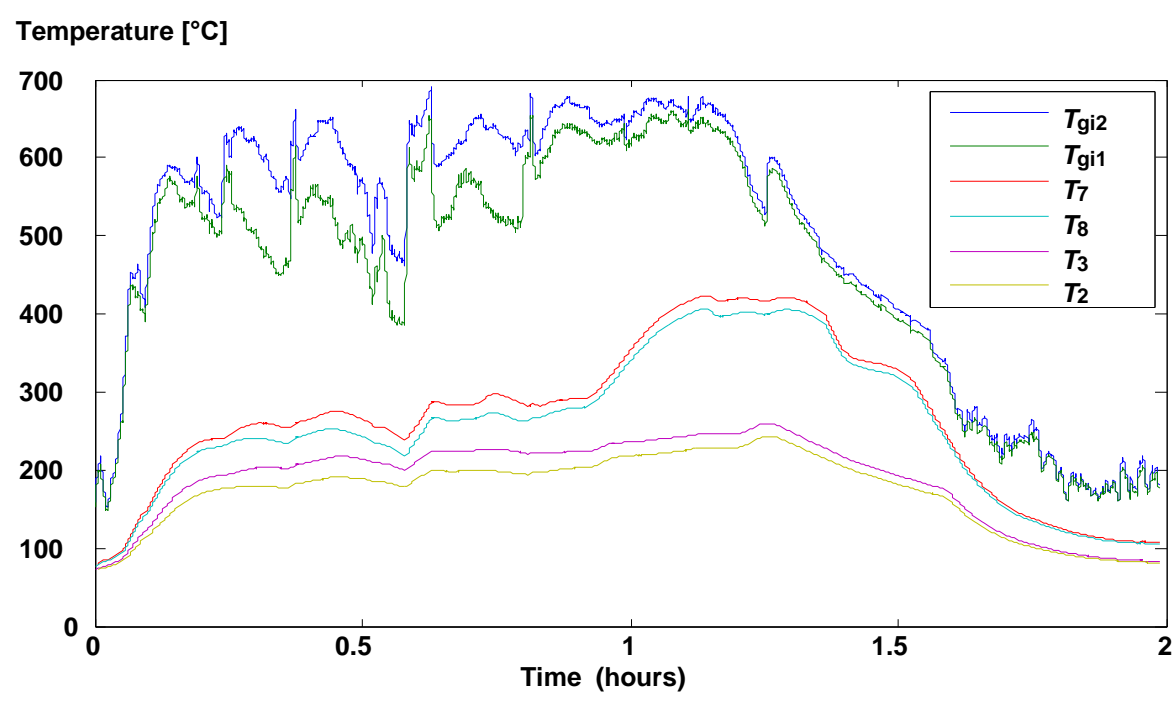

Figure 7. Main temperatures in the TEG

\section{Estimated production of electricity}

To have an estimate of the production of electricity, it is necessary to determine the temperature of the cold side of TE modules $\left(T_{\mathrm{c}}\right)$. Because of the difficulty to measure this temperature directly, a rough estimate of its value was calculated from the values given by the temperature sensor on the wall of the tank. The thickness of the stainless steel water tank is $6 \mathrm{~mm}$ and the thermal conductivity of this steel is around $16 \mathrm{~W} / \mathrm{mK}$. Knowing the hot side temperature and the property of the TE module, a linear approximation has been done.

Using the matched load power of the modules given by Thermonamics (Figure 8), the estimated production of electricity has been calculated for the first 55 minutes of the experiment (before the red dotted line in Figure 6). For each heat exchanger, the average temperature was calculated and also the matched electrical power. Figure 9 represents the temperatures of the upper right heat exchanger. $T_{\text {hur }}$ is the average hot side temperature: the mean of $T_{5}, T_{8}$ and $T_{4} . T_{\mathrm{c}}$ is the estimated cold side temperature of the TE module and $P_{\text {elec }}$ is the output electrical power of one TE module. The electrical energy can be calculated by integration.

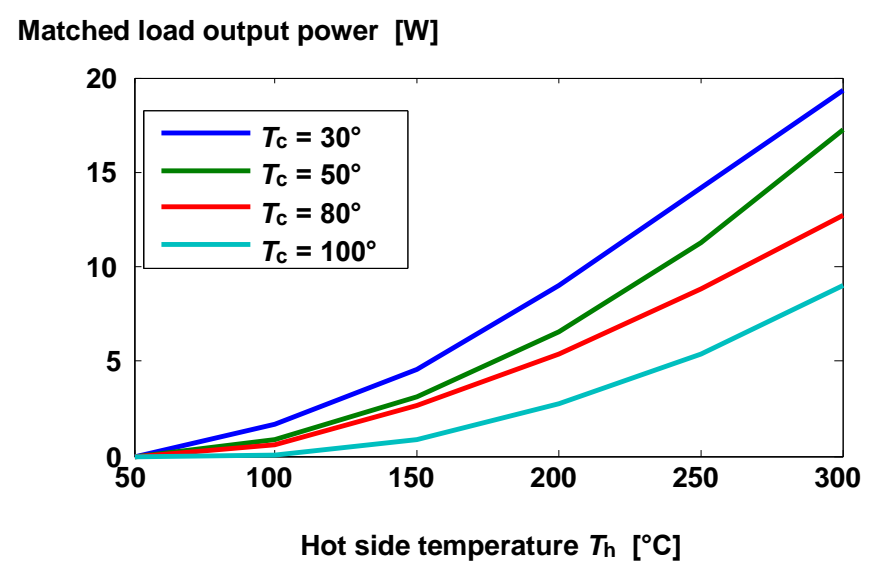

Figure 8. Matched load output power versus $T_{\mathrm{h}}$ under various $T_{\mathrm{c}}$ 


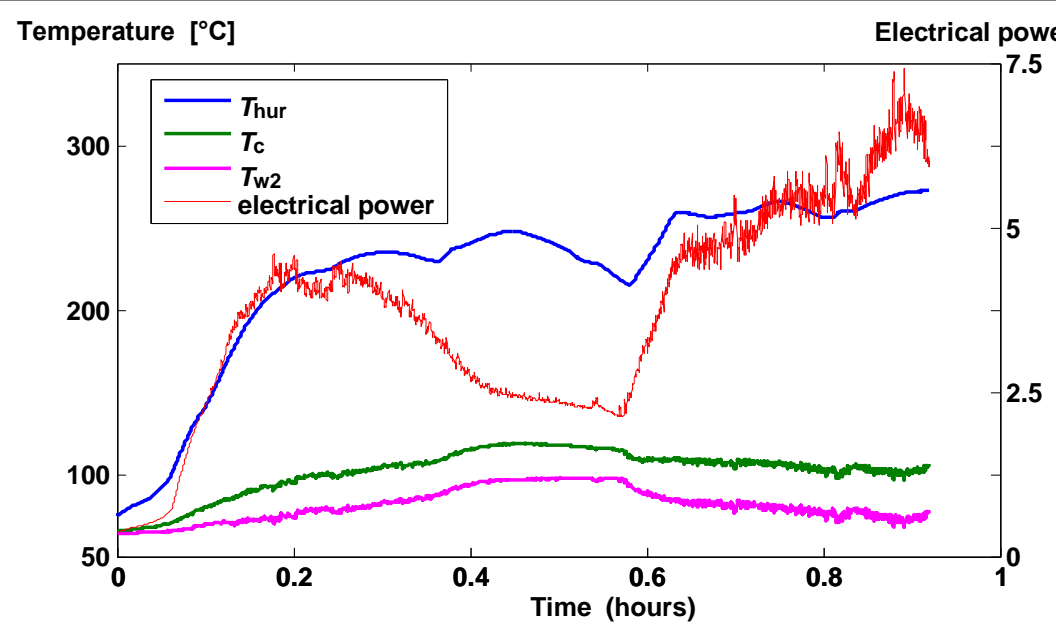

Figure 9. Temperatures and power of the upper right exchanger

Because there are two modules of exchangers, the electrical energy for each heat exchanger must be multiplied by two. Table 3 represents the energy produced by each exchanger according to its location as well as the average power. The global average power is around $28 \mathrm{~W}$. This result is very encouraging because it shows that we can hope for a sufficient power to feed the motor of the fan. The power consumed by the fan is about $15 \mathrm{~W}$. Part of the produced power can be used for other low energy applications like LED or phone charging.

Table 3. Produced energy and power

\begin{tabular}{ccccc}
\hline & \multicolumn{2}{c}{ Energy [J] } & \multicolumn{2}{c}{ Power [W] } \\
\hline & Left & Right & Left & Right \\
\hline Top & 15,863 & 12,242 & 9.6 & 7.4 \\
Bottom & 10,532 & 8,458 & 6.3 & 5.1 \\
\hline
\end{tabular}

However it is necessary to be careful; a much more extensive measurement campaign must be carried out to test the complete behaviour of the stove. Various kinds of wood must be tested as well as different types of cooking and transient behaviour must be studied before being able to replace the ceramic glass by real modules.

The device uses $8 \mathrm{TE}$ modules $\left(250 \mathrm{~cm}^{2}\right)$ to produce approximately $28 \mathrm{~W}$ (110 $\mathrm{mW} / \mathrm{cm}^{2}$ ). It is advisable to make theoretical calculations to check if it is possible to obtain an equivalent or even greater power with fewer modules [20]. This would also reduce the cost.

\section{CONCLUSIONS}

Opportunities to equip wood stoves with TEG have been studied. These generators which are capable of producing a small amount of electricity should allow us to run the fan of the stove. Under laboratory conditions, tests were performed showing that in normal operation the stove will produce approximately $28 \mathrm{Wh}$. This power is sufficient to power the fan. The future installation of a TEG should make the stove autonomous. Thanks to this autonomy, it is possible to use it in rural areas that are not connected with electricity network. The dissemination of this stove in areas where biomass is the only source of energy would halve the consumption of wood, would make the use of wood prunings possible and thus would reduce deforestation. 


\section{ACKNOWLEDGEMENTS}

The authors acknowledge the financial support of the Conseil Régional d'Aquitaine and of the Conseil Général des Pyrénées Atlantiques.

\section{REFERENCES}

1. Planète bois, http://www.planetebois.org, [Accessed: 03-Sept-2013]

2. Snyder, G. J., Thermoelectrics Handbook Macro to Nano, ch. Thermoelectric Power Generation: Efficiency and Compatibility, CRC Press, 2006.

3. Biswas, K., He, J., Blum, I. D., Wu, C. I., Hogan, T. P., Seidman, D. N., Dravid, V. P. and Kanatzidis, M. G., High-performance Bulk Thermoelectrics with All-scale Hierarchical Architectures, Nature, Vol. 489, pp 414-418, 2012, http://dx.doi.org/10.1038/nature11439

4. Spacecraft Overview, http://voyager.jpl.nasa.gov/spacecraft/index.html, [Accessed : 03-Sept-2013].

5. Schwartz, L. I. and Shure, H. J, Survey of Electric Power Plants for Space Applications, Fifty-Eight National Meeting of the American Institute of Chemical Engineers, Philadelphia, Pennsylvania, December 5-9, 1965.

6. Cataldo, R. L. and Bennett, G. L., U.S. Space Radioisotope Power Systems and Applications: Past, Present and Future, Radioisotopes - Applications in Physical Sciences, book edited by Nirmal Singh, ISBN 978-953-307-510-5, 2011.

7. Crane, D., Thermoelectric Generator Performance for Passenger Vehicles, 3rd Thermoelectrics Applications Workshop, Amerigon, Irwnidale, CA, 2012.

8. Maranville, C., Thermoelectric Opportunities for Light-duty Vehicles, Ford Motor Company, 2012.

9. Mazar, B., State of the art Prototype Vehicle with a Thermoelectric Generator, 3rd Thermoelectrics Applications Workshop 2012, BMW, Munich, Germany, 2012.

10.Eder, A. and Linde, M., Efficient and Dynamic - the BMW Group Roadmap for the Application of Thermoelectric Generators., 2nd Thermoelectrics Applications Workshop, BMW Group, 2011.

11.The World Bank, http://www.worldbank.org/en/topic/energy, [Accessed: 03-Sept-2013].

12.Mastbergen, D. and Willson, B., Generating Light from Stoves using a Thermoelectric Generator, ETHOS 2005 Engineers in Technical and Humanitarian Opportunities of Service international stove research conference, 2005.

13.Joshi, S., Mastbergen, D. and Willson, B., Field testing of Stove-powered Thermoelectric Generators., ETHOS 2007 Engineers in Technical and Humanitarian Opportunities of Service international stove research conference, 2007.

14.Rinalde, G., Juanica, L., Taglialavore, E., Gortari, S. and Molina, M., Development of Thermoelectric Generators for Electrification of Isolated Rural Homes, International Journal of Hydrogen Energy, Vol.35, No.11, pp 5818-5822, 2010, http://dx.doi.org/10.1016/j.ijhydene.2010.02.093

15.O’Shaughnessy, S., Deasy, M., Kinsella, C., Doyle, J. and Robinson, A., Small Scale Electricity Generation from a Portable Biomass Cookstove: Prototype Design and Preliminary Results, Applied Energy, Vol. 102, No. 0, pp 374-385, 2013, http://dx.doi.org/10.1016/j.apenergy.2012.07.032

16.Champier, D., Bédécarrats, J.-P., Rivaletto, M. and Strub, F., Thermoelectric Power Generation from Biomass Cook Stoves, Energy, Vol. 35, No. 2, pp 935-942, 2010, http://dx.doi.org/10.1016/j.energy.2009.07.015

17.Champier, D., Bédécarrats, J.-P., Kousksou, T., Rivaletto, M., Strub, F. and Pignolet, P., Study of a te (thermoelectric) Generator Incorporated in a Multifunction Wood Stove, 


$\begin{array}{llll}\text { Energy, } & \text { Vol.36, } & \text { No. 3, } & \text { pp 1518-1526, }\end{array}$
http://dx.doi.org/10.1016/j.energy.2011.01.012

18.Champier, D., Favarel, C., Bédécarrats, J.-P., Kousksou, T. and Rozis, J., Prototype combined Heater/thermoelectric Power Generator for Remote Applications, Journal of Electronic Materials, Vol. 42, No. 7, pp 1-12, 2013, http://dx.doi.org/10.1007/s11664-012-2459-x

19.Min, G., Thermoelectrics Handbook Macro to Nano, ch. Thermoelectric Module Design Theories, CRC Press, 2006.

20.Favarel, C., Bédécarrats, J.-P., Kousksou, T. and Champier, D., The influence of Operating Parameters and Occupancy Rate of Thermoelectric Modules on the Electricity Generation, Proceedings of ECOS 2012, 2012. 